\title{
Are C-KIT, MMP-9 and Type II Collagen Positive Undifferentiated Cells Involved in Cartilage Growth? A Description of Unusual Interstitial Type of Cartilage Growth
}

Soha A Soliman ${ }^{1}$ and Hanan H Abd-Elhafeez ${ }^{2 *}$

${ }^{1}$ Department of Histology, Faculty of Veterinary Medicine, South Valley University, Qena, Egypt

${ }^{2}$ Department of Anatomy and Histology, Faculty of Veterinary Medicine, Assuit University, 71526, Egypt

\section{Abstract}

Cartilages growth requires activation of perichondrial cells and chondrocyte multiplication. Activated perichondrial cells produce an outer cartilage matrix and in appositional growth and chondrocytes division produce new chondrogenic cells which participate in interstitial growth of cartilage. This study was performed to identify a third type of cartilage growth in skeletal elements of quail embryos at $6,7,8,9,10,13,16,17$ days of incubation. Paraffin sections of the whole embryos were stained using H\&E and Safranin O stains. Immunohistochemical staining for C-KIT, matrix metallpoproteinase-9 (MMP-9) and type II collagen was performed. Other samples were processed for scanning and transmission electron microscopy. We found that cells extended form mesenchymal tissue or perichondrium penetrated the cartilage templates of different skeletal elements. The morphological and immunohistochemical characteristics of these cells were identical to mesenchymal cells; characterized by their small size, having multiple cell processes and staining positive for C-KIT. MMP-9 positive cells were detected in cartilage matrix. The mesenchymal cells further differentiated into chondrocytes which were positive for type II collagen immunostaining and secreted Safranin O positive cartilage matrix. In conclusion, our results suggest that C-KIT positive mesenchymal cells secrete MMP-9 to penetrate growing cartilage, produce type II collagen and proteoglycan and have a role in interstitial growth of embryonic cartilage templates in quail. (Graphical Abstract).

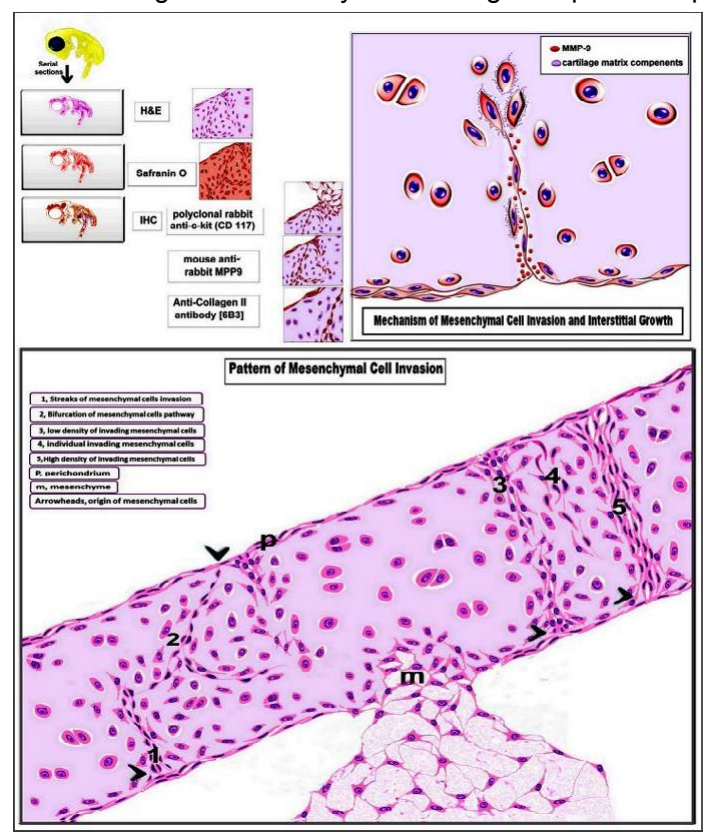

Keywords: Cartilage; Mesenchymal cells; Quail; Embryos

\section{Introduction}

Cartilaginous growth and renewal depend on the production of new chondrocytes. This is achieved either by interstitial division of existing chondrocytes, which result in the lengthening of the cartilage (interstitial growth), or by differentiation of perichondrial stem cells which are responsible for diametric growth of the cartilage (appositional growth) [1]. The invasion of undifferentiated cells during cartilage development is associated with endochondral ossification in long bone. The invading cells induce the osteogenic cell lineage to transform the cartilaginous tissue to bone tissue [2]. MMP or matrixins are a class of
*Corresponding author: Hanan $\mathrm{H}$ Abd-Elhafeez, Department of Anatomy and Histology, Faculty of Veterinary Medicine, Assuit University, 71526, Egypt.,Tel: +201006500848; E-mail: hhmmzz91@gmail.com

Received October 13, 2016; Accepted November 17, 2016; Published November 27,2016

Citation: Soliman SA, Abd-Elhafeez HH (2016) Are C-KIT, MMP-9 and Type II Collagen Positive Undifferentiated Cells Involved in Cartilage Growth? A Description of Unusual Interstitial Type of Cartilage Growth. J Cytol Histol 7: 440 doi: 10.4172/2157-7099.1000440

Copyright: (C) 2016 Soliman SA, et al. This is an open-access article distributed under the terms of the Creative Commons Attribution License, which permits unrestricted use, distribution, and reproduction in any medium, provided the original author and source are credited. 
metal-dependent endopeptidases. They cause proteolytic degradation of ECM components which is essential for tissue remodeling during physiological or pathological conditions. MMPs subtypes, such as collagenases, gelatinases, stromelysins, and membrane type MMPs (MT-MMPs), have different structural domains and substrate [3]. Gelatinase enzymes are gelatinase A (MMP-2) and gelatinase B (MMP9). MMP-9 responsible for angiogenesis, the migration of immune cells, the activation of cytokines and chemokines, and cancer progression [4]. MMP- 9 degrades various components of extracellular matrix such as collagen types IV, V, XIk', XIVl', elastin, aggrecan, link protein, decorinr, lamininn, entactin, SPARCq, myelin basic proteinm, $\infty 2 \mathrm{Mn}$, $\infty 1 \mathrm{Pli}$, IL-1 $\beta$ j, proTNF- $\infty \mathrm{k}[5]$.

Previous studies provide evidence for the involvement of mesenchymal cells in cartilage growth. In the air-breathing organ of catfish, the invading mesenchymal cells differentiate into chondrogenic cells, which contribute to the growth and renewal of the supporting elastic cartilage. Moreover, interstitial mesenchymal cells differentiation is involved in replacement of hyaline cartilage by the elastic type [6]. Moreover, mesenchymal cells invasion occurs in the tibia and femur of quail embryos prior to the onset of endochondral ossification process and responsible for interstitial cartilage growth. Undifferentiated cells of perichondrial origin invade the central region of the cartilage template. These invading cells acquire a chondrogenic lineage and secrete new cartilage matrix [7]. The purpose of the current study was to investigate a similar mode of cartilage growth contributed in the growth of different skeletal cartilaginous elements in quail embryos (Coturnix coturnix japonica).

\section{Materials and Methods}

For the purpose of the study, we chose embryonic stages in which cartilage templates of different skeletal elements developed. Day 6 is considered the beginning of cartilage template formation in quail embryos [7]. Therfore, we collected samples in the early stages of the development from day 6 to day 9 (stage 25 to 28 according to [8] to evaluate the occurrence of mesenchymal cells in different cartilaginous elements. We used later embryonic stages, specifically days 13, 16, and 17; the last day of incubation (stage 32, 35, 36 according to [8] characterize the mesenchymal cells in cartilage templates. All processed samples for light microscopy analysis and morphological examination allowed for determination of the cell lineage and its properties. We used immunostaining to identify mesenchymal cells and embryonic chondrogenic cells, while and cellular invasion was identified using a polyclonal rabbit anti-c-kit (CD 117), a monoclonal mouse antichicken antibody against type II collagen and mouse anti-rabbit antibody against matrix metalloproteinase-9 (MPP-9).

\section{Preparation of paraffin embedding samples}

The study used fertile quail (Coturnix coturnix japonica) eggs obtained from the Research Quail Farm connected to the Department of Histology, Faculty of Veterinary Medicine, South Valley University in, Qena, Egypt. The fertilized eggs were incubated in a c10 "POULTRY TECHNICAL OFFICE, Alexandria, Egypt" at $37.5^{\circ} \mathrm{C}$ with a relative humidity of $65 \%$. The eggs were rotated automatically every 6 hours after the 3 rd day of incubation. We collected 21 quail embryos at day 6 , $7,8,9,13,16$ and 17 of incubations (Figure 1). Embryonic stages were determined upon the onset of incubation. Then 6-9day embryos were kept at $-20^{\circ} \mathrm{C}$ for 4 hours prior to collecting. Egg shells were opened at the broad end, and apparently healthy embryos were carefully excised from their shells. Embryos at day 13 and 16 were euthanized by decapitation. All embryos were immediately fixed in $10 \%$ buffered

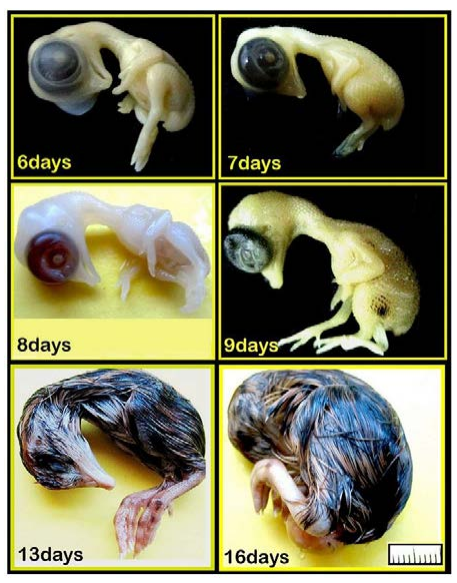

Figure 1: Quail embryos.

formalin for 3 days and Bouin's solutions for 8 hours. Fixed samples were dehydrated in ascending grades of alcohols at 70\%, 80\%, $90 \%$ and $100 \%$ for 90 minutes at each concentration. The sampled were cleared using methyl benzoate. Dehydrated samples were then impregnated

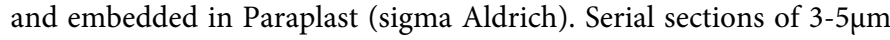
were cut using a Richert Leica RM 2125 Microtome, Germany and mounted on glass slides. Sections were kept in an incubator at $40^{\circ} \mathrm{C}$ for dryness and stained with H\&E [9] and safranin O [10]. Stained sections were examined using DMLS light microscope (Leica, Germany) outfitted with MC120 HD camera (Leica, Germany).

\section{Immunohistochemistry}

Immunohistochemical staining was performed on paraffin sections of 8-day quail embryos were mounted on SuperfrostTM plus microscope slides. Antigen localization was performed using a polyclonal rabbit anti-c-kit antibody against CD 117, a mouse anti-rabbit against MMP-9, and a monoclonal mouse anti-chicken antibody against type II collagen. Visualization of the reaction was performed using the reagent of UltraVision Detection System (AntiPolyvalent, HRP/DAB (ready to use) Thermo Fischer Scientific TP015-HD) according to the manufacture's instructions, combined with the Avidin-Biotin Complex (ABC) technique [11]. Sections $(5 \mu \mathrm{m})$ of paraffin-embedded tissue were dewaxed, rehydrated and rinsed

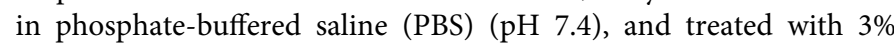
hydrogen Peroxide to inhibit endogenous peroxidase. For antigen retrieval, slides were placed in $10 \mathrm{mM}$ sodium citrate buffer $(\mathrm{pH} 6.0)$ and heated to $95-98$ in a water bath for 20 minutes followed by cooling for $20 \mathrm{~min}$ at room temperature. Sections were then rinsed in PBS ( $\mathrm{pH}$ 7.4). Sections were covered with Ultra V block (refer to Table 1 Part I, Thermo Fisher scientific, USA) for 5 minutes at room temperature to block non-specific background staining. Sections were incubated with the primary antibodies at room temperature for 1 hour or overnight according to their respective data sheet. Antibody sources, dilution, and incubation duration are shown in Table 1 Part III, and as described previously [12]. Slides were washed with PBS ( $\mathrm{pH}$ 7.4), followed by incubation for 10 minutes at room temperature with a biotinylated secondary antibody applied drops-wise on the section. Slides were rinsed in PBS ( $\mathrm{pH}$ 7.4), followed by drops-wise addition of the drops of streptavidin- peroxidase complex (Thermo Fisher scientific, USA) and incubated for 10 minutes at room temperature followed by another rinse in PBS pH 7.4. Visualization of the bound antibodies 


\begin{tabular}{|c|c|c|c|c|c|c|c|c|c|}
\hline \multirow[t]{2}{*}{ Part I } & \multicolumn{9}{|c|}{ Reagent of UltraVision Detection System (Anti-Polyvalent, HRP/DAB (ready to use) Thermo Fischer Scientific TP-015-HD. } \\
\hline & \multicolumn{2}{|c|}{ Component } & \multicolumn{7}{|c|}{ P-015-HD } \\
\hline & \multicolumn{2}{|c|}{ Hydroen Peroxide Block } & \multicolumn{7}{|c|}{ TA-015-HP } \\
\hline & \multicolumn{2}{|l|}{ Ultra V Block } & \multicolumn{7}{|c|}{ TP-015-UB } \\
\hline & \multicolumn{2}{|c|}{ Biotinylated goat Anti-Polyvalent } & \multicolumn{7}{|c|}{ TP-015-BN } \\
\hline & \multicolumn{2}{|c|}{ Streptaidin Peroxidase } & \multicolumn{7}{|c|}{ TS-015-HR } \\
\hline & \multicolumn{2}{|l|}{ DAB Plus Substrate } & \multicolumn{7}{|c|}{ TP-015-HSX } \\
\hline & \multicolumn{2}{|c|}{ DAB Plus Chromogen } & \multicolumn{7}{|c|}{ TA-001-HCX } \\
\hline \multirow[t]{11}{*}{ Part II } & \multicolumn{9}{|c|}{ Solutions used in immunohistochemistry (Bancroft et al.) } \\
\hline & \multicolumn{2}{|c|}{$\begin{array}{l}\text { PBS-buffer ( } \mathrm{pH} 7,2-7,6) \text { : Used in } \\
\text { immunohistochemstry }\end{array}$} & \multicolumn{3}{|l|}{$\mathrm{NaCl}$} & \multicolumn{4}{|l|}{$42.5 \mathrm{~g}$} \\
\hline & & & \multicolumn{3}{|c|}{$\mathrm{Na}_{2} \mathrm{HPO}_{4} 2 \mathrm{H}_{2} \mathrm{O}$} & \multicolumn{4}{|l|}{$6.35 \mathrm{~g}$} \\
\hline & & & \multicolumn{3}{|c|}{$\mathrm{NaH}_{2} \mathrm{PO}_{4} \mathrm{H}_{2} \mathrm{O}$} & \multicolumn{4}{|l|}{$1.95 \mathrm{~g}$} \\
\hline & & & \multicolumn{3}{|c|}{ Dest. water } & \multicolumn{4}{|l|}{ add 5 I } \\
\hline & \multicolumn{2}{|c|}{ Citrate-buffer $(\mathrm{pH} 6,0)$ : } & \multicolumn{3}{|c|}{$\begin{array}{l}\text { Solution } \mathrm{A} \text { : } \\
\text { Citrate } \mathrm{C}_{6} \mathrm{H}_{8} \mathrm{O}_{7} \mathrm{H}_{2} \mathrm{O} \\
\text { Aqua dest. }\end{array}$} & \multicolumn{4}{|l|}{$\begin{array}{l}21.01 \mathrm{~g} \\
\text { ad } 1 \mathrm{l}\end{array}$} \\
\hline & & & \multicolumn{3}{|c|}{$\begin{array}{l}\text { Solution B: } \\
\text { Sodium citrate } \mathrm{Na}_{3} \mathrm{C}_{6} \mathrm{H}_{5} \mathrm{O}_{7} 2 \mathrm{H}_{2} \mathrm{O} \\
\text { dest. water }\end{array}$} & \multicolumn{4}{|l|}{$\begin{array}{l}29.41 \mathrm{~g} \\
\text { ad } 1 \mathrm{I}\end{array}$} \\
\hline & & & $\begin{array}{l}\text { Using } \\
\text { Solutic } \\
\text { Solutic } \\
\text { dest. v }\end{array}$ & $\begin{array}{l}\text { olution: } \\
\text { A: } \\
\text { ater }\end{array}$ & & $\begin{array}{l}9 \mathrm{ml} \\
41 \mathrm{ml} \\
\text { ad } 500 \mathrm{ml}\end{array}$ & & & \\
\hline & $\begin{array}{l}\text { PBS-buffer ( } \mathrm{pH} 7 \\
\text { Used for scanning }\end{array}$ & 7,6): & $\begin{array}{l}\text { Solutic } \\
\mathrm{Na}_{2} \mathrm{HF} \\
\text { Aqua }\end{array}$ & $\begin{array}{l}\mathrm{A:} \\
\mathrm{O}_{4} 2 \mathrm{H}_{2} \mathrm{O} \\
\text { est. }\end{array}$ & & $\begin{array}{l}17.02 \mathrm{~g} \\
\text { ad } 600 \mathrm{ml}\end{array}$ & & & \\
\hline & & & $\begin{array}{l}\text { Solutic } \\
\mathrm{NaH}_{2} \mathrm{P} \\
\text { dest. }\end{array}$ & $\begin{array}{l}\mathrm{B}: \\
\mathrm{O}_{4} \mathrm{H}_{2} \mathrm{O} \\
\text { ater }\end{array}$ & & $\begin{array}{l}6 \mathrm{~g} \\
\operatorname{ad} 250 \mathrm{ml}\end{array}$ & & & \\
\hline & & & $\begin{array}{l}\text { Using } \\
\text { Solutic } \\
\text { Solutic } \\
\text { dest. v }\end{array}$ & $\begin{array}{l}\text { olution: } \\
\text { A: } \\
\text { B: } \\
\text { ater }\end{array}$ & & $\begin{array}{l}580 \mathrm{ml} \\
219 \mathrm{ml} \\
\text { ad } 500 \mathrm{ml}\end{array}$ & & & \\
\hline Part III & & & entity, s & ources, and working & dilut & tion of anti & dies used in th & study & \\
\hline & Target & & & Prima & $y$ an & ttibody & & & Biotinylated \\
\hline & & & & Origin & & Dilution & Incubation & Antigen retrieval & secondary antibody \\
\hline & $\begin{array}{l}\text { CD117 } \\
\text { (Anti-c-Kit) }\end{array}$ & $\begin{array}{l}\text { Genremed B } \\
\text { Inc, South Sa } \\
\text { USA }\end{array}$ & $\begin{array}{l}\text { logies, } \\
\text { isco, }\end{array}$ & Rabbit polyclonal & $1: 5$ & & $\begin{array}{l}1 \mathrm{~h} \text { at room } \\
\text { temperature }\end{array}$ & $\begin{array}{l}\text { boiling in citrate } \\
\text { buffer (pH 6.0), } \\
20 \text { min }\end{array}$ & Goat anti polyvalent \\
\hline & Anti- MPP9 & $\begin{array}{l}\text { Thermo Fiscl } \\
\text { Lab vision C } \\
\text { Fremont, US }\end{array}$ & tific, & $\begin{array}{l}\text { Mouse } \\
(\mathrm{mc}, \mathrm{Ab}-1) \\
\text { Clone D(33)376 } \\
\text { Rabbit polyclonal }\end{array}$ & $1: 3$ & & Over night & $\begin{array}{l}\text { boiling in citrate } \\
\text { buffer ( } \mathrm{pH} 6.0) \\
20 \text { min }\end{array}$ & Goat anti polyvalent \\
\hline & $\begin{array}{l}\text { Collagen II Ab } \\
3-3(\text { Clone } 6 \text { b3) }\end{array}$ & $\begin{array}{l}\text { Thermo Fiscl } \\
\text { Lab vision C } \\
\text { Fremont, US }\end{array}$ & tific, & $\begin{array}{l}\text { Mouse anti chicken } \\
\text { (mouse monoclonal }\end{array}$ & $1: 2$ & & Over night & $\begin{array}{l}\text { boiling in citrate } \\
\text { buffer }(\mathrm{pH} 6.0) \text {, } \\
20 \text { min }\end{array}$ & Goat anti polyvalent \\
\hline
\end{tabular}

Table 1: Chemicals and reagents.

\begin{tabular}{|l|l|l|l|l|l|l|l|}
\hline Age of embryos & $6^{\text {th }}$ & $7^{\text {th }}$ & $8^{\text {th }}$ & $9^{\text {th }}$ & $13^{\text {th }}$ & $16^{\text {th }}$ & $17^{\text {th }}$ \\
\hline $\begin{array}{l}\text { Number of embryos had invasive } \\
\text { mesenchyme in the skeletal elements }\end{array}$ & $2 / 3$ & $2 / 3$ & $5 / 6$ & $3 / 3$ & $2 / 3$ & $1 / 3$ & $0 / 3$ \\
\hline
\end{tabular}

Table 2: Number of embryos showed mesenchymal invasion in the cartilaginous elements.

was performed using one drop of diaminobenzidine (DAB) Plus chromogen mixed with $2 \mathrm{ml}$ of DAB Plus substrate. Applied directly on the tissue and incubated for $5-10$ minutes at room temperature. Note: all incubations were performed in a humid chamber to avoid tissue dessication. Sections were counterstained in Harris hematoxylin for 30 seconds, dehydrated and mounted with DPX. Negative controls were performed by omitting the primary antibodies. Immunohistochemical stains were examined by light microscopy (Leica, Germany) outfitted with MC120 HD camera (Leica, Germany).

\section{SEM preparation}

The heads of 3 quail embryos at day 8 were longitudinally and transversely cut into small pieces which were then fixed in Karnovasky fixative (10 ml paraformaldehyde $25 \%, 10 \mathrm{ml}$ glutaraldehyde $50 \%$,


as shown in Table 2 [12]. Specimens were washed in $0.1 \mathrm{M}$ sodium -phosphate buffer ( $\mathrm{pH} 7.2$ ), post-fixed in $1 \%$ osmic acid in $0.1 \mathrm{M}$ sodium-phosphate phosphate buffer and followed by another in $0.1 \mathrm{M}$ sodium-phosphate buffer (PH 7.2). Samples were then dehydrated in alcohol as described previously and immersed in iso-amyl acetate. The dehydrated samples underwent critical point drying using a Polaron apparatus (Critical Point Drying Procedure Polaron E3000 CPD Apparatus, Quorum Technologies, Germany). As a final step, samples were coated with gold using an JEOL-1100 E-ion sputtering device and 
images were captured by a JEOL scanning electron microscope (SEM; JSM- $5400 \mathrm{LV}$ ) at $10 \mathrm{KV}$.

\section{Preparation of resin embedded and transmission electron specimens}

Representative specimens of heads from 8-day quail embryos were longitudinally and transversely cut into small pieces which were used for semithin sections. Small pieces 2.0-3.0 mm long were fixed in Karnovsky fixative, [13] at $4^{\circ} \mathrm{C}$ overnight. Specimens were washed $(4 \times 15$ minutes) in $0.1 \mathrm{M}$ phosphate buffer ( $\mathrm{pH} 7.2)$. All samples were post-fixed $1 \%$ in osmium tetroxide at $4^{\circ} \mathrm{C}$ for 2 hours in the dark followed by washing $(3 \times 20$ minutes $)$ in $0.1 \mathrm{M}$ phosphate buffer $(\mathrm{pH}$ 7.2). Samples were dehydrated in a graded series of ethanol $(50 \%, 70 \%$, $90 \%$, and $100 \%$ ) followed by propylene oxide embedding in Epon and polymerization at $60^{\circ} \mathrm{C}$ for 24 hours and then at $75^{\circ} \mathrm{C}$ for $48 \mathrm{hr}$.

Semi-thin sections $(1 \mu \mathrm{m})$ were cut using an ultra-microtome Ultracut E (Reichert-Leica, Germany) and stained with toluidine blue [sodium tetra borate (borax) $1 \mathrm{~g}$, toluidine blue $1 \mathrm{~g}$, distilled water 100 $\mathrm{ml}]$ [9].

Ultra-thin sections $(60-70 \mathrm{~nm})$ were cut from selected blocks using an Ultrotom V R V (LKB Bromma, Germany), and routinely contrasted with uranyl-acetate and lead citrate [14] prior to examination with a JEOL 100CX II transmission electron microscope at the Electron Microscopy Unit of Assiut University.

In the current study,

\section{Results}

We examined the skeleton in different ages of quail embryos (Figure 1). During embryonic development, cartilage templates of many skeletal elements were formed. Undifferentiated cells continues with the surrounding mesenchyme or perichondrium were observed within the cartilage template of both male and female embryos. The cells had the characteristic morphological features of the mesenchymal cells. They appeared flattened or spindle-shaped with oval nucleus contained euchromatin and sometimes heterochromatin. The cells were connected with each other by cytoplasmic processes (Figures $2 \mathrm{E}$, 2F, 3A-D, 3G, 4A-D and 4F). In flat bone, individual mesenchymal cells could be observed in the cartilage templates. Cellular deformation was seen during the cellular invasion (Figure 2A). The amount of the mesenchymal cells varied as masses of low (Figure 2B) or high cellular densities (Figure 2C). Sometimes, the mesenchymal cells were packed forming cellular streaks. Mesenchymal cell streaks may be parallel or randomly organized (Figure $2 \mathrm{G}$ and $2 \mathrm{H}$ ). Bifurcations of the mesenchymal cells pathway could be observed (Figure 3G). The mesenchymal cells transformed to chondrocytes (Figure 2D) and produced safranin $\mathrm{O}$ positive proteoglycan-rich matrix (Figure 3D). In long bones, cellular invasion occurred in resting or proliferating or hypertrophic zone of the growing cartilage (Figure 3D, 3F and 3H).

By SEM, Undifferentiated mesenchymal cells were identified as small flattened cells located inside the cartilage (Figure 4A, 4B and $4 \mathrm{~F}$ ). Cell processes connecting between mesenchymal cells and differentiating chondrocytes (Figure 4C and 4D). Mesenchymal cells could be seen contiuned with the perichondrium (Figure 4C).

Semithin and ultrathin sections showed showed mesenchymal cells and differentiating chondrocytes inside the occipital cartilage. Mesenchymal cells appreared flattened with cell processes and the nucleus was oval with euchromatin (Figure 5A and 5D). Mesenchymal



Figure 2: Higher magnifications illustrated a pattern of mesenchymal cells invasion. Paraffin sections of quail embryos in 8 days of incubation stained with safranin O "A", H\&E "B-H". The arrows refer to individual mesenchymal cells in vertebral cartilage "A", mesenchymal cell areas of low cellular density in basioccipital "B", high cellular density in basioccipital " $\mathrm{C}$ " and differentiating chondrocytes acquired rounded shape and were surrounded by few matrix in vertebral cartilage "D". E, F: The cells in basioccipital had the common morphological characteristics of mesenchymal cells; flattened or spindleshaped, with an oval vesicular nucleus in "F", sometimes the nucleus contained condensed chromatin in "E". Note: cytoplasmic processes "arrowheads". G, H: mesenchymal cells in flat bone (basioccipital bone). Note: Mesenchymal cells (arrows) in parallel streaks in "G", random streaks in "H".

cells were connected with the perichondrial cells (Figure 5B and 5C). Differentating chondrocytes were flattened, oval or rounded in shape had cell processes connected with other chondrocytes (Figure 5E).

Interstitial mesenchymal cells differentiation was observed in the nasal (Figure 6A and 6B), occipital (Figure 6C and 6D), turbinate (Figure 6E and 6F), lacrimal (Figure 6G and 6H), sternum (Figure 6I and $6 \mathrm{~J}$ ), frontal (Figure $7 \mathrm{~A}$ and $7 \mathrm{~B}$ ), premaxilla (Figure $7 \mathrm{~A}$ and $7 \mathrm{C}$ ), maxilla (Figure 7D and 7F), dentary (Figure 7G-7I), ribs (Figure 8A and $8 \mathrm{~B}$ ), humerus (Figure $8 \mathrm{C}$ and $8 \mathrm{D}$ ), radius, ulna (Figure $8 \mathrm{E}$ and $8 \mathrm{~F}$ ), femur (Figures $8 \mathrm{G}, 8 \mathrm{H}, 9 \mathrm{G}$ and $9 \mathrm{H}$ ), tibiotarsal, digit (Figure $9 \mathrm{~A}$ and $9 \mathrm{~B}$ ), vertebrae (Figure 9C and 9D), clavicle, (Figure 9E and 9F). Multiple focal sites of cellular invasion c (Figure 8I and 8J) an be seen in the cartilaginous elements (Figures 2G, 2H, 3G, 6D, 6F, 7G, 7H, 8A-8I, $9 \mathrm{~A}$ and $9 \mathrm{~B})$. Existence of mesenchymal cells in cartilage templetes could be observed in 6th day (Figure 6A-6D), $7^{\text {th }}$ day (Figure 6E-6J), became more prominent in 8 th day (Figures $2-4,7,9 \mathrm{C}, 9 \mathrm{D}, 10$ and 11 ), $9^{\text {th }}$ day (Figures 8, 9A and 9B) and continued to later stages of embryonic development as it can be observed clavicle of 13 (Figure 9E and 9F) and 16 (Figure 9G and 9H) day of incubation. Cartilage templetes with mesenchymal cell was not observed all examined embryos as shown in Table 2. 


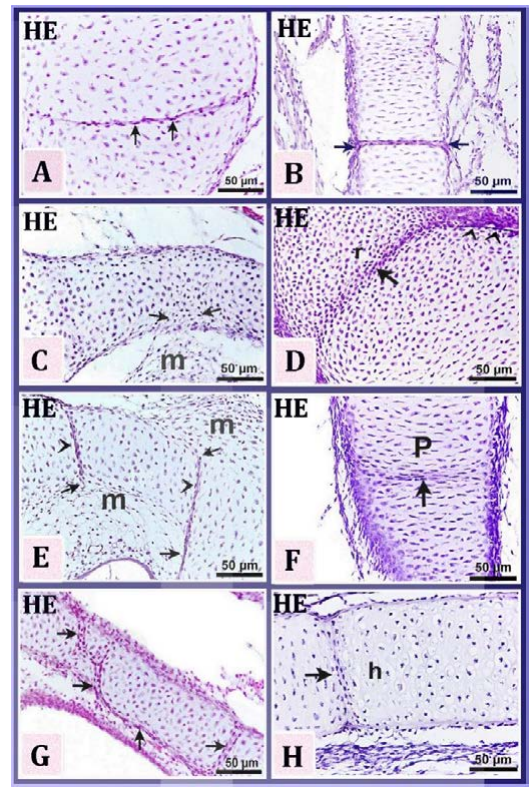

Figure 3: Higher magnifications illustrated origin and sites of the mesenchymal cells invasion. Paraffin sections of quail embryos in 8 days of incubation stained with H\&E. A, B: Mesenchymal cells of perichondrial origin. Note mesenchymal cells may invade the whole circumference of the sternal cartilage in"B" or partial invasion of the basioccipital cartilage"A". C, E: The developing cartilage of the basioccipital lacked the perichondrial covering in certain areas where mesenchymal cells got the way to penetrate the cartilage. The mesenchymal cells may form streaks "arrowheads" in"C". Mesenchyme $(\mathrm{m})$. The growing cartilage (c). Note: the arrows refer to the point of perichondrial continuation to mesenchymal cells in "A-D". The arrowheads refer to the mesenchymal cells. $\mathrm{D}, \mathrm{F}, \mathrm{H}$ : mesenchymal cells in long bones. Note: Streak of mesenchymal cells in the perichondrium (arrowheads) in "D", the mesenchymal cells in resting zone of the femur "D", proliferating zone of the radius " $F$ ", hypertrophic zone of the femur "H". G: The pathway of the mesenchymal cells undergoes bifurcation "arrows" in turbinate " $F$ ". The arrowheads refer to the mesenchymal cells.

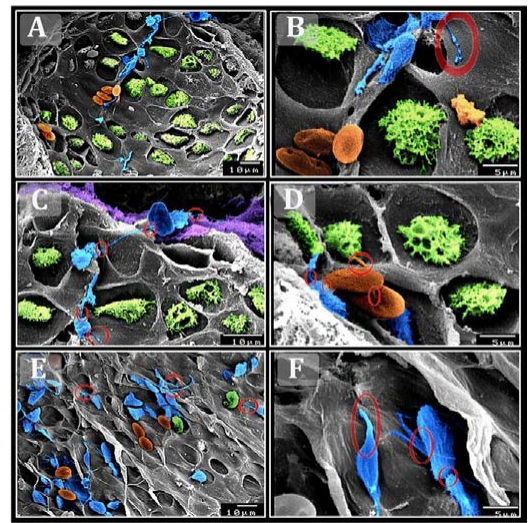

Figure 4: Mesenchymal cells and differentiating chondrocytes in scanned cartilage sample. Scanned electron sample of basioccipital cartilage in 8 days old quail embryo. A-C: Mesenchymal cells streaks in the cartilage template. E, $\mathrm{F}$ : high density of mesenchymal cells inside the cartilage templetes. Colored cells in blue "mesenchymal cells", orange "differenting chondrocytes and green "mature chondrocytes". The violet tissue "perichondrila covering" and the red rings "cytoplasmic processes". The cellular processes connected between mesenchymal cell, differentiating and hyoertrophic chondrocytes.

CD117 as a marker for mesenchymal cells was used to detect the distribution of mesenchymal cells in the embryonic skeletal elements. CD117 positive mesenchymal cells were observed in the mesenchyme around the cartilage templates where perichondrium was not established

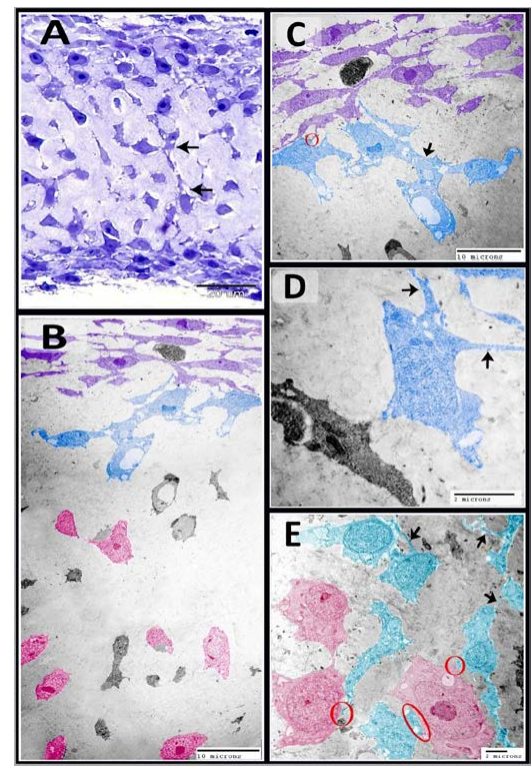

Figure 5: Mesenchymal cells and differentiating chondrocytes in resin embbded cartilage template. Semithin section $(A)$ and ultrathin sections (B-E) in occipital cartilage in 8 days old quail embryos. A: mesenchymal cells "arrows" were located within the cartilage template. B: mesenchymal cells "blue colored cells" connected with the perichondrial cells "violet colored cells", chondrocytes "pink colored cells". C: Higher magnification of "B", mesenchymal cells "blue colored cells" connected with the perichondrial cells "violet colored cells", the connection site "red circle". D: Typical mesenchymal cell "blue colored cell" located in the cartilage matrix. The cell appeared small flattened; the nucleus contained euchromatin and had multiple cell processes "arrows". E: differentiating chondrocytes "Peacock Blue colored cells" connected with each other by cell processes "arrows". Chondrocytes "pink colored cells" connected "red circles" with other differentting chondrocytes.

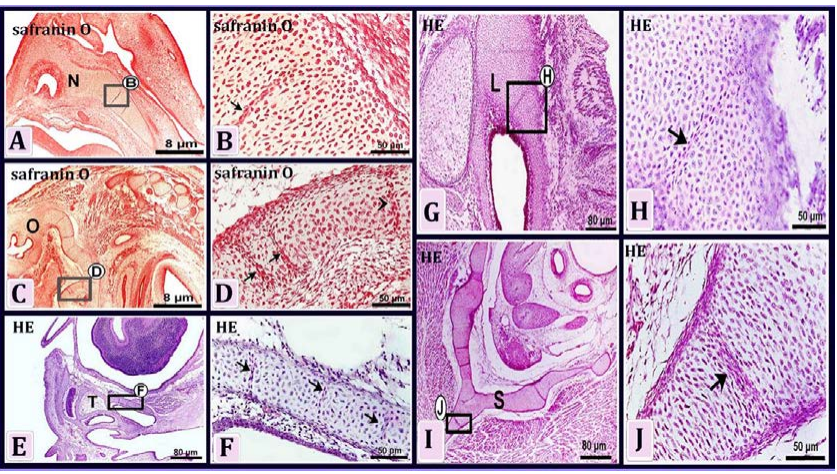

Figure 6: Mesenchymal cells invasive in sternum and skull cartilage templates. Paraffin sections of quail embryos in 6 days "A-D", 7 days, "E-J" of incubation stained with safranin O. A, B: mesenchymal cells "arrows" in primitive cartilage templates of the nasal $(\mathrm{N})$ bone. "B" represented a high magnification of the squared areas in "A". C, D; mesenchymal cells "arrows" in primitive cartilage templates of the occipital $(O)$ bone. Arrowheads refer to the differentiating chondrocytes surrounded by Safranin positive cartilage matrix. " $D$ " represented a high magnification of the squared areas in "C". $E$, $\mathrm{F}$ : mesenchymal cells "arrows" in primitive cartilage templates of the turbinate $(t)$. "F" represented a high magnification of the squared areas in "E". G, H mesenchymal cells "arrows" in primitive cartilage templates of the lacrimal $(L)$. "H" represented a high magnification of the squared areas in "G". I, J: mesenchymal cells "arrows" in primitive cartilage templates of the sternum (S) "J" represented a high magnification of the squared areas in "I".

(Figure 10C-10F). CD117 positive mesenchymal cells continued with the perichondrium. The morphological characteristics of the invading cells were identical to mesenchymal cells (Figure 10A and 10B). Intense 




Figure 7: Mesenchymal cells invasive in skull cartilage templates. Paraffin sections of quail embryos in 8 days of incubation stained with H\&E. A, B, C: mesenchymal cells "arrows" in primitive cartilage templates of the frontal $(F)$ and premaxilla $(P)$. "C, B" represented a high magnification of the squared areas in "A". D, E, F: mesenchymal cells "arrows" in primitive cartilage templates of the frontal $(F)$ and maxilla $(M)$. "E, F" represented a high magnification of the squared areas in "D". G, H, I: mesenchymal cells "arrows" in primitive cartilage templates of the dentary $(\mathrm{d})$. " $\mathrm{H}$, I" represented a high magnification of the squared areas in " $\mathrm{G}$ ".

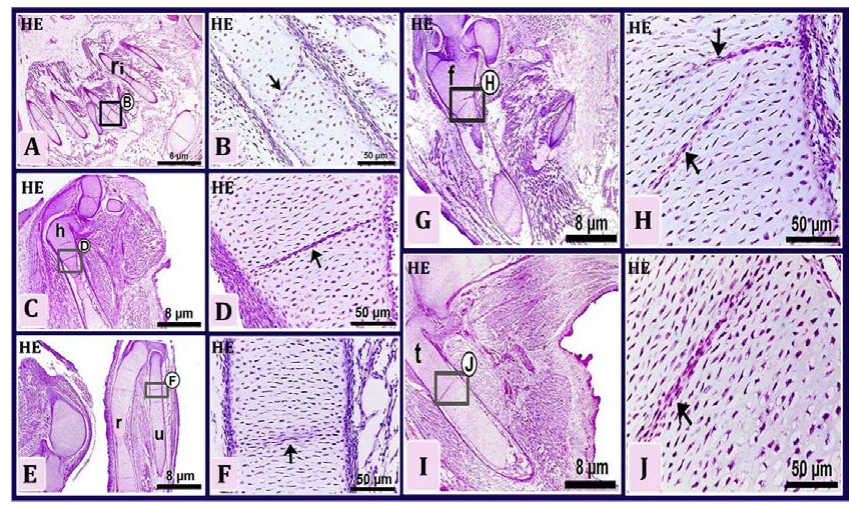

Figure 8: Mesenchymal cell invasion in long bone cartilage templates. Paraffin sections of quail embryos in $9(\mathrm{~A}-\mathrm{H})$ day of incubation stained with $\mathrm{H} \& \mathrm{E}$. A, B: mesenchymal cells "arrows" in primitive cartilage templates of the ribs (ri). "B" represented a high magnification of the squared areas in "A". C, D: mesenchymal cells "arrows" in primitive cartilage templates of the humerus $(H)$. "D" represented a high magnification of the squared areas in "C". "D" represented a high magnification of the squared areas in "C". E, F: mesenchymal cells "arrows" in primitive cartilage templates of the radius $(r)$ and ulna (U). "F" represented a high magnification of the squared areas in "E". G, H: mesenchymal cells "arrows" in primitive cartilage templates of the Femur $(F)$. "H" represented a high magnification of the squared areas in " $G$ ". I, $\mathrm{J}$ : mesenchymal cells "arrows" in primitive cartilage templates of the tibiotarsal

(T). "J" represented a high magnification of the squared areas in "I".

immunostained perichondrial cells surrounded the cartilage templates (Figure 10A and 10E). Some chondrocytes stained for CD117 (Figure $10 \mathrm{E})$. Immunostaining of 8-day embryonic quail cartilage using Anti-Collagen II antibody [6B3] revealed positive mesenchymal cells which located inside the cartilage matrix, perichondrial cells, and chondrocytes (Figure 11A, 11C, 11E and 11F). MMP-9 strong positive mesenchymal cells were detected in the perichondrial connective tissue and inside cartilage matrix (Figure 12A-12D). In certain areas, cartilage matrix degradation was observed around the invading mesenchymal cells (Figure 12E and 12F).

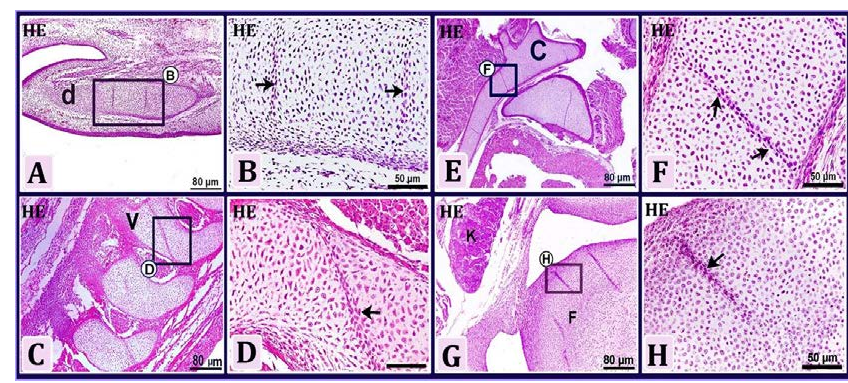

Figure 9: Mesenchymal cell invasion in digit, vertebrae, clavicle, femur cartilage templates. Paraffin sections of quail embryos in 8 "C, D", 9 "A-B", 13 "E, F" and 16 "G, H" day of incubation stained with H\&E. A, B: mesenchymal cells "arrows" in primitive cartilage templates of the digit (d). "B" represented a high magnification of the squared areas in "A". C, D: mesenchymal cells "arrows" in primitive cartilage templates of the vertebrae (V). "D" represented a high magnification of the squared areas in "C". E, F: mesenchymal cells "arrows" in primitive cartilage templates of the clavicle $(C)$. "F" represented a high magnification of the squared areas in "E". G, H: mesenchymal cells "arrows" in primitive cartilage templates of the femur $(F)$. " $H$ " represented a high magnification of the squared areas in "G".

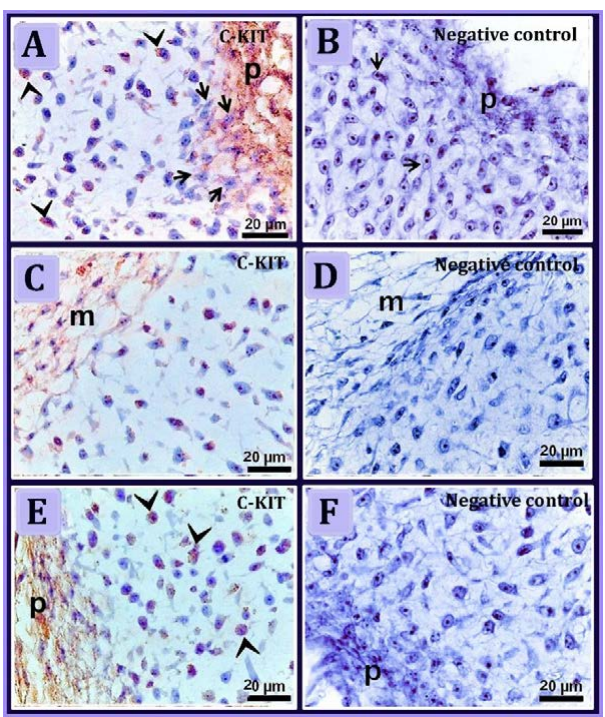

Figure 10: Immunohistochemical staining of cartilage templates with $C D$ 117. Immunohistochemical staining of paraffin sections "A, C, E", and control negative "B, D, F" of 8 days quail skulls with CD117. A: Strong CD117 positive cells which appeared small with cell processes, strong CD117 positive perichondrial cells $(P)$. B: Arrows refer to mesenchymal cells with cell processes inside the cartilage template, perichondrium $(P)$. C: Strong CD117 positive mesenchyme $(\mathrm{m})$ covering the cartilage templetes. $\mathrm{D}$ : mesenchyme $(\mathrm{m})$ covered the cartilage templates. E: Strong positive periochondrium $(P)$, arrowheads refer to positive chondrocytes. F: perichondrium $(P)$ surrounded the cartilage templete.

\section{Discussion}

Cartilage growth and renewal especially early stages of cartilage development, are of significant interest to researchers. This study described an unusual mode of cartilage growth during embryonic development of skeletal elements in quail, and comparing it with the commonly known modes of cartilage growth, and used immunohistochemical staining of different molecular markers to identify the type of cells involved in this form of cartilage growth. $\mathrm{C}$-KIT or KIT is a type of tyrosine kinase receptor expressed on the cell surface. C-KIT is activated upon binding by the corresponding ligand a stem cell factor, to regulate cellular differentiation, proliferation, 


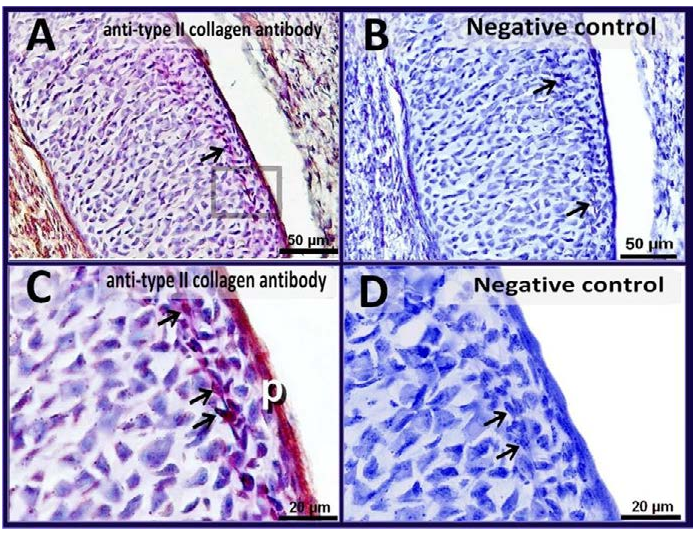

Figure 11: Immunohistochemical of cartilage templates with Anti-Collagen II antibody [6B3] and with MMP-9. Immunohistochemical staining of paraffin of 8 days quail dentary cartilage with Anti-Collagen II antibody [6B3] "A, C" and negative control "B, D" and rib cartilage template with MMP-9 "E, G" and negative control "F, H" and occipital bone stained by H\&E "I, J". A: arrow referred of area of collagen II positive mesenchymal cells in the cartilage template. B: arrows referred to mesenchymal cells. C: arrows refer to strong collage II positive mesenchymal cells and perichondrium. D: arrows refer to mesenchymal cells with cell processes.

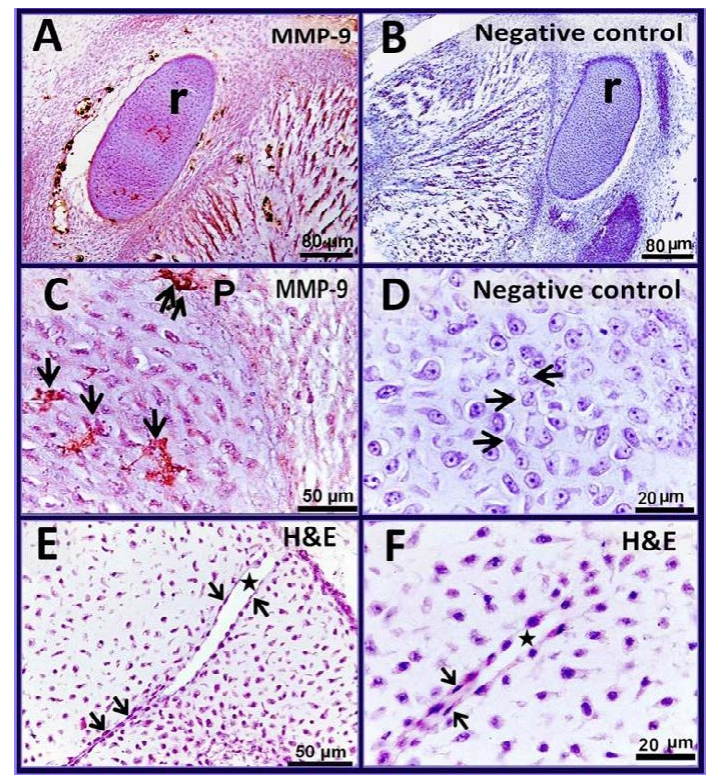

Figure 12: Immunohistochemical of cartilage templates with MMP-9. Immunohistochemical staining of paraffin of 8 days quail rib cartilage template with MMP-9 "A, C" and negative control "B, D" and occipital bone stained by $H \& E$ "E, F". A, B: rib cartilage template (R). C: arrows refer to intense MMP-9 immunostained inside the cartilage template; arrowheads refer to MMP-9 positive chondrocytes. D: arrows refer to typical mesenchymal cells with cell processes. E, F: Cartilage matrix degradation "asterisk" in areas of mesenchymal cells "arrows" invasion.

chemotaxis, cell adhesion and apoptosis. Different C-KIT-dependent cell types have been identified such as mast cells, some hematopoietic stem cells, germ cells, melanocytes, Cajal cells of the gastrointestinal tract, and oncogenic cells $[15,16]$. In the current study, we used C-KIT immunostaining in the skull of quail embryos to localize mesenchymal cells in and around cartilage elements. C-KIT-positive cells were identified in perichondrial cells, the mesenchyme around the cartilage template and mesenchymal cells inside the cartilage matrix. Typical morphological features of mesenchymal cells were identified using paraffin sections and TEM, and SEM. They appeared small in size and possessed cell processes extending from either the surrounding mesenchyme or the perichondrium. Localization of mesenchymal cells inside the cartilage could be observed in different patterns; with areas of high cellular density, low cellular density or as individual cells. Mesenchymal cells may be connected by cell processes and appeared as cellular streaks. Multiple sites of mesenchymal cells localization were observed in cartilage templates.

We used histochemical and Immunohistochemical staining to identify the cell lineage of mesenchymal cells. For the detection of cartilage-specific proteins, we used antibody against type II collagen [6B3] which is known to positively stain fetal and juvenile chondrocytes. Immunostaining of embryonic quail cartilage showed positive staining for type II collagen in invading mesenchymal cells which were located inside the cartilage matrix, besides perichondrial cells and chondrocytes. Moreover, the invading mesenchymal cells differentiated into cells producing safranin O-positive proteoglycanrich matrix. This finding indicated that the invading mesenchymal cells had a chondrogenic potentiality and can produce cartilage-specific proteins. Thus, the invading mesenchymal cells contribute at least in part to the growth of quail embryonic cartilage. This is addition to the known modes of cartilage growth, where undifferentiated cells in the perichondrium produce new circumferential cartilage matrix which is responsible for cartilage growth in appositional manner while the division of chondrocytes within the matrix drives interstitial growth $[17,18]$.

MMP or matrixins are a family of metal-dependent endopeptidases which can degrade extracellular matrix components and have a role in tissue remodeling during physiological or pathological conditions. Twenty-four groups of matrix metalloproteinase enzymes are recognized in humans [19]. MMPs are categorized depending on the structural domains and substrate specificity into collagenases, gelatinases, stromelysins, and membrane type MMPs (MT-MMPs) [3]. Gelatinases are sub-grouped into gelatinase A (MMP-2) and gelatinase B (MMP-9). MMP-9 is involved in angiogenesis, the migration of immune cells, the activation of cytokines and chemokines, and cancer progression (Klein and Bischoff, 2011). MMP- 9 degrades collagen types IV, V, XIk', XIVl', elastin, aggrecan, link protein, decorinr, lamininn, entactin, SPARCq, myelin basic proteinm, $\infty 2 \mathrm{Mn}, \infty 1 \mathrm{Pli}$, IL- $1 \beta \mathrm{j}$, proTNF- $\infty \mathrm{k}$ [5]. In the current study, we used immunohistochemical staining to identify MMP-9 expression in embryonic quail cartilage. MMP-9-positive mesenchymal cells were detected in the perichondrial connective tissue and within the cartilage matrix suggesting that mesenchymal cells have invasive properties and are likely to have a perichondrial origin. MMP-9 was associated with degradation of cartilage matrix during osteoarthritis [20]. Invasion is characteristic of other cells that secrete MMPs such as endothelial cells which promote neural progenitor cell migration and angiogenesis [21], cancer cells [22,23], embryonic trophoblasts [24], fibroblasts, neutrophils, eosinophils, macrophages, T-cells, chondrocytes and osteoblasts [25].

Invasion of mesenchymal cells in the cartilage templates of long bones is usually associated with vascular cells. The invaded cells acquire an osteogenic cell lineage having a role in the endochondral ossification process [26,27]. Vascular channels, which are also known as cartilage channels, are formed in developing cartilage before ossification. Cartilage canals originate as perichondrial papillae from the surrounding connective tissue to provide nutrients to the cartilage. The perivascular cells erode the cartilage matrix [28], and progressively penetrate the cartilage matrix to develop the epiphyseal and diaphyseal 
cartilage canals [7]. MMP-9 has been found in the induction of cartilage canals formation [29]. Cartilage canals consist of blood vessels, perivascular cells (in particular mesenchymal cells) [30], monocytes, and macrophages [28]. Moreover, cells of osteogenic lineage have been identified in cartilage canals. These cells predominately express type I collagen and the bone-specific protein, periostin [31-33]. Morover, type II collagen reacting cells are detected in cartilage canals by [34-36]. In our study, we found that mesenchymal cells were not restricted to the epiphysis and the diaphysis. Furthermore, there was no evidence that vascular invasion accompanied mesenchymal cell migration.

A pervious study found invasive mesenchymal cells of chondrogenic potentiality. The cellular invasion was confined to the central hypertrophic zone of the cartilage template of the developing femur and tibia in quail embryos. The invading cells were uniformly distributed along the hypertrophic zone [8], which is contrast to the current study, in which where cellular invasion was observed in a focal manner mainly at multiple sites. A similar process of cartilage growth is observed in the cartilaginous tissue of the air-breathing organ in catfish. Mesenchymal cells invade the cartilage at multiple sites and differentiate to chondrogenic cells which secrete a new cartilage matrix. Interstitial mesenchymal differentiation occurred at the sites of the vacated lacunae as a result of chondrocyte deaths. Mesenchymal cells invade the hyaline cartilage to be replaced by an elastic type. This invasive interstitial differentiation of the mesenchymal cells contributed to cartilage growth, renewal, and replacement [35]. In conclusion, we found that C-KIT positive mesenchymal cells secrete MMP-9 to invade the growing cartilage. Further these cells, produce type II collagen and proteoglycan, and have a role in the interstitial growth of cartilage templates during early and late stages of skeletal development in quail embryos.

\section{Clinical Correlations}

Degenerative cartilaginous disorders are a major concern in skeletal diseases. Undifferentiated mesenchymal cells have been used in recent research towards the development of therapeutic applications toward replacing damaged cartilage. In the current study, we found that undifferentiated mesenchymal cells invaded the growing cartilage to provide a new population of chondrogenic progenitors and secrete new cartilage matrix. Investigations in the molecular regulatory pathway(s) involved in undifferentiated mesenchymal cells invasion and differentiation may provide valuable insight to future researchers to improve the mesenchymal cell response and ultimately, may lead to new therapeutic applications for cartilage disorders.

The authors declare that the research was conducted in the absence of any commercial or financial relationships that could be construed as a potential conflict of interest.

\section{Acknowledgement}

We would like to express my gratitude and deep thanks to Prof. Dr. Salma Ahmed Mohamed Alghadrifi, Prof. of Anatomy, Department of Anatomy, Faculty of Veterinary Medicine, South Valley University for her kind help and support.

\section{References}

1. Eroschenko VP, Di Fiore MSH (2013) Difiore's atlas of histology with functional correlations. Lippincott williams \& wilkins (12thedn) p: 114.

2. Long F, Ornitz DM (2013) Development of the endochondral skeleton. Cold spring harb perspect biol. 51 a008334.

3. Newman MGH, Takei PR, Klokkevold, Carranza FA (2014) Carranza's clinical periodontology. Elsevier health sciences 84

4. Klein T, Bischoff R (2011) Physiology and pathophysiology of matrix metalloproteases. Amino acids 412: 271-290.
5. Clendeninn NJ, Appelt K (2001) Matrix metalloproteinase inhibitors in cancer therapy. Springer science+business media new york, Humana press.

6. Soliman SA (2014) New aspect in cartilage growth" the invasive interstitial type J Aquac Res Development 109: 272-277.

7. Soliman SA (2013) Histomorphological and morphometrical studies on endochondral ossification in the japanese quail. Ph.d. Thesis, south valley university, egypt. Lap lambert academic publishing pp. 66-84

8. Ainsworth SJ, Stanley RL, Evans DJ (2010) Developmental stages of the japanese quail. $\mathrm{J}$ anat 216: 13-15

9. Bancroft JD, Layton C, Suvarna SK (2013) Bancroft's theory and practice of histological techniques, expert consult: online and print, (7thedn) bancroft's theory and practice of histological techniques. Elsevier health sciences.

10. An YH, Martin KL (2003) Handbook of Histology Methods for Bone and Cartilage. Springer Science \& Business Media.

11. HSU SM, Raine L, Fanger H (1981) Use of avidin-biotin-peroxidase complex $(A B C)$ in immunoperoxidase techniques: a comparison between $A B C$ and unlabeled antibody (PAP) procedures. J Histochem Cytochem 29: 577-580.

12. Karnovsky MJ (1965) A Formaldehyde-Glutaraldehyde Fixative of High Osmolarity for use Electron Microscopy. Cell Biol 27: 1-3.

13. Reynolds EG (1963) The use of lead citrate at high $\mathrm{pH}$ as an electron-opaque stain in electron microscopy. J Cell Biol 17: 208-212.

14. Miettinen M, Lasota J (2005) KIT (CD117): a review on expression in norma and neoplastic tissues, and mutations and their clinicopathologic correlation Appl Immunohistochem Mol Morphol 13: 205-220.

15. Margaritescu C, Pirici D, Simionescu C, Stepan A (2011) The utility of CD44 CD117 and CD133 in identification of cancer stem cells (CSC) in oral squamous cell carcinomas (OSCC). Rom J Morphol Embryol 52: 985-993.

16. Marjit B (2009) General Anatomy Genetics Histology and Embryology. Academic Publishers pp. 1-26.

17. Rawlani S, Rawlani SJ (2011) Textbook of General Anatomy. P Medical Ltd p. 45.

18. Ozet OG (2013) Matrix Metalloproteinase Enzyme Family. Archives Medical Review Journal 22: 209-220.

19. Galasso O, Familiari F, De Gori Mand G. Gasparini (2012) Recent findings on the role of gelatinases (matrix metalloproteinase-2 and -9) in osteoarthritis. Adv Orthopedics 834208

20. Wang L, Zhang ZG, Zhang RL, Gregg SR, Hozeska-Solgot A, et al. (2006) Matrix metalloproteinase 2 (MMP2) and MMP9 secreted by erythropoietinactivated endothelial cells promote neural progenitor cell migration. J Neurosci 26: 5996-6003.

21. Itoh $Y$, Nagase $H$ (2002) Matrix metalloproteinases in cancer. Essays Biochem 38: $21-36$.

22. Leong HS, Robertson AE, Stoletov K, Leith SJ, Chin CA, et al. (2014) Invadopodia are required for cancer cell extravasation and are a therapeutic target for metastasis. Cell Rep 8: 1558-1570.

23. Zhu JY, Pang ZJ, Yu YH (2012) Regulation of trophoblast invasion: the role of matrix metalloproteinases. Rev Obstet Gynecol 5: 137-143.

24. Singh G, Rabbani SA (2007) Bone Metastasis. Cancer Drug Discovery and Development, Springer Science \& Business Media.

25. Carlevaro MF, Cermelli S, Cancedda R, Descalzi Cancedda F (2000) Vascular endothelial growth factor (VEGF) in cartilage neovascularization and chondrocyte differentiation: auto-paracrine role during endochondral bone formation. J Cell Sci 113: 59-69.

26. Kanczler JM, Oreffo RO (2008) Osteogenesis and angiogenesis: the potential for engineering bone. Eur Cell Mater 15: 100-114.

27. Gabner S, Häusler G, Böck P (2014) Vascular channels in hyaline cartilage development of channels. and removal of matrix degradation products. Anat Histol Embryol 43.

28. Melton JT, Clarke NM, Roach HI (2006) Matrix metalloproteinase-9 induces the formation of cartilage canals in the chondroepiphysis of the neonatal rabbit. $J$ Bone Joint Surg Am 88: 155-161.

29. Blumer MJ, Longato S, Richter E, Perez MT, Konakci K, et al. (2005) The role 
Citation: Soliman SA, Abd-Elhafeez HH (2016) Are C-KIT, MMP-9 and Type II Collagen Positive Undifferentiated Cells Involved in Cartilage Growth? A Description of Unusual Interstitial Type of Cartilage Growth. J Cytol Histol 7: 440. doi: 10.4172/2157-7099.1000440

Page 9 of 9

of cartilage canals in endochondral and perichondral bone formation: are there similarities between these two processes? J Anat 206: 359-372.

30. Blumer MJ, Fritsch H, Pfaller K, Brenner E (2004) Cartilage canals in the chicken embryo: ultrastructure and function. Anat and Embryol 207: 453-462.

31. Blumer MJ, Longato S, Fritsch $\mathrm{H}$ (2004) Cartilage canals in the chicken embryo is involved in the process of endochondral bone formation within the epiphyseal growth plate. Anat Rec A Discov Mol Cell Evol Biol 279: 692-700.

32. Blumer MJ, Schwarzer C, Perez MT, Konakci KZ, Fritsch H (2006) Identification and location of bone-forming cells within cartilage canals on their course into the secondary ossification centre. J Anat 208: 695-707.

33. Le Guellec D, Mallein-Gerin F, Treilleux I, Bonaventure J, Peysson P, et al.
(1994) Localization of the expression of type I, II and III collagen genes in human normal and hypochondrogenesis cartilage canals. Histochem $\mathrm{J} 26$ : $695-704$.

34. Soliman SA, Abd-Elhafeez HH (2014) Mesenchymal cells in cartilage growth. LAP Lambert Academic Publishing 4.

35. Arnhold S, Gluer S, Hartmann K, Raabe O, Addicks K, et al. (2011) AmnioticFluid Stem Cells: Growth Dynamics and Differentiation Potential after a CD117-Based Selection Procedure. Stem Cells Int 715341.

36. Claassen H, Kirsch T, Simons G (1996) Cartilage canals in human thyroid cartilage characterized by immunolocalization of collagen types I, II, pro-III, IV and X. Anat Embryol (Berl) 194: 147-153. 